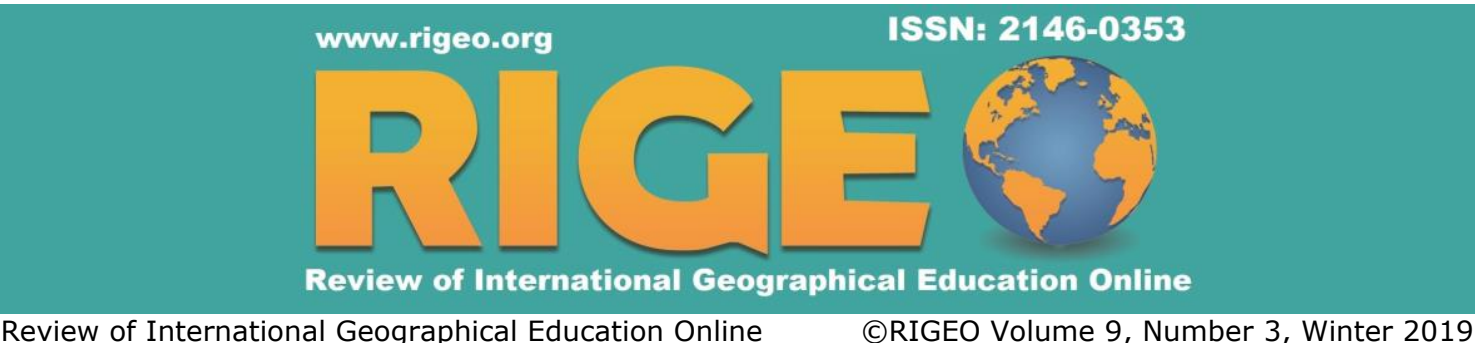

Review of International Geographical Education Online

(C) RIGEO Volume 9, Number 3, Winter 2019

Research Article

Copyright @ RIGEO 2019

To cite this article: Aksoy, B. (2019). Determination of Map Literacy of Undergraduate Geography Students. Review of International Geographical Education Online (RIGEO), 9(3), 591-603. Retrieved from http://www.rigeo.org/vol9no3/Number3Winter/RIGEO-V9-N3-6.pdf

DOI: $10.33403 /$ rigeo.582301

Submitted: June 26, 2019

Revised: October 28, 2019

Accepted: November 22, 2019

\title{
Determination of Map Literacy of Undergraduate Geography Students
}

\author{
Bülent AKSOY ${ }^{1}$ \\ Gazi university, Ankara, TURKEY
}

\begin{abstract}
The purpose of this study was to determine the level of map literacy of pre-service geography teachers. The research was carried out using the relational survey model. The data collection tool used in the research was the map literacy scale. The research was conducted on 391 undergraduate geography students in 2016-2017 academic year. Multiple linear regression analysis technique was applied in solving the sub problems of the research. According to the findings of the research; when the correlations between the predictive variables and the dependent variable were examined, a positive and moderate correlation was seen between the level of map literacy of geography pre-service teachers and variables such as competence in the frequency of using map, the frequency of activity by maps, and the level of interest in geography. When the partial correlations between the predictive variables and the dependent variable were examined, it was determined that the undergraduate geography students had a positive and weak relationship between map literacy levels and the frequency of using map and the frequency of activity by maps variables. On the other hand, it was determined that undergraduate geography students had a positive and moderate relationship between map literacy levels and the level of interest in geography variable. In addition, under graduate geography students had a moderate and meaningful relationship with their map literacy level together with the frequency of using map, the frequency of activity by maps, and the level of interest in geography variables. According to the results of the research, it is seen that the activities that geography undergraduate students perform with the maps are a moderate predictor of map literacy. For this reason, it is suggested that emphasis should be given to the courses and practices that will develop the map skills in the geography undergraduate programs.

Keywords

Map Literacy, Map Use, Activities with Map, Geography Interest
\end{abstract}

${ }^{1}$ Assoc. Prof., Gazi University, Gazi Educational Faculty, Turkish and Social Sciences Department, Ankara-Turkiye, baksoy28 [at] gmail.com , ORCID: 0000-0002-7181-8008

(C) Review of International Geographical Education Online

RIGEO 2019

ISSN: 2146-0353

www.rigeo.org 
The introduction of the first map goes back to 10,000 B.C. When examining the ancient maps, it is seen that mankind needs a map before writing in order to meet various needs such as settlement, raw materials, natural resources and wars in daily life. There are various definitions of map. However, both the development of mapping techniques and the mapping of different planets with the technological developments have limited the older definitions.

Therefore, the requirement of more inclusive reformation of definitions and explanations regarding the map has arisen. A map is the projection of the physical details about a part or the whole of an area inhabited by or concerning humankind, and the information about said details or the phenomena that occur in said area, usually on a flat surface with a given scale.

The details and information are indicated in symbols, and the positioning is made according to a directing and reference system (General Directorate of Mapping). Maps form the corner stone of our perception for a place. The concept of reading and understanding a map is different than reading a text. To understand a map, which has an important role in daily life, we should know the way of our brains' perception of details on a map. There are two major elements required for a map reader to immediately notice the features on the maps. The first is cartographers making a contrast in the formation-surface relation while creating maps and the map reader detecting such contrasts.

The second element regarding the perceptual image is the classification of the regions, borders and formations arising from contrasts based on the communication process between the eye and brain set forth by Gestalt.

The concept of literacy is one of the prominent themes of late years. The literacy standards regarding various subjects or disciplines are determined. In this scope, one of the prominent types of literacy is map literacy. It is difficult to find a definition regarding map literacy commonly agreed by all the related parties. Koç \& Bulut (2014) defines the map literacy as the ability of using maps in daily life and understanding maps. Map literacy consists of knowledge, understanding, implementation, analysis, synthesis and evaluation processes. Preferring the concept of map skills instead of map literacy, Weeden (1997) classifies the map skills as map use, mapping, map reading and map interpretation. Olson (1976) determined three levels of map literacy gradually becoming more difficult such as comparing the symbol characteristics individually, identifying the characteristics of symbol groups on a map as a whole and using maps as a means of information configuration in decision-making process. Buckley, Muehrcke \& Muehrcke (2011) describe map literacy in three stages which are map reading, map analysis and map interpretation. In the scale developed to measure map literacy of individuals, Koç \& Demir (2014) approach map skills in four categories which are dealing with maps, map reading and interpretation, outline mapping and map use. Rautencbach, Coetzee and Çöltekin (2017) study on map skills in six categories which are symbol recognition, determination of direction and route, location detection, measurement and anticipation, calculation and explanation, interpretation (Koç, Aksoy \& Çifçi, 2017). 
There are may studies regarding map skills and map literacy conducted by various researchers (Carswell 1971; Gilmartin \& Patton 1984; Gerber\&Wilson, 1989; Liben\&Downs, 1989; McClure, 1992; Wood, 1992; White, 1995; Weeden, 1997; Catling, 1998; Clarke, 2003; MacEachren, 2004; Krygier\&Wood, 2005; Gökçe, 2015; Wiegand, 2006; Kızılçaoğlu, 2007; Golledge, Marsh, \& Battersby, 2008; Richard B. Schultz, Joseph J. Kerski \& Todd C. Patterson, 2008; Koç, 2008; Koç, 2010; Buckley, Muehrcke \& Muehrcke, 2011; Sönmez, \& Aksoy, 2012; Aksoy, 2013; Koç \& Karatekin, 2015; Koç \& Çifçi, 2016; Koç, Aksoy \& Çifçi 2017, Aksoy \& Koç, 2017; Kartal \& Koç, 2017). Only two studies are available in the field of scale development in the literature regarding map literacy. These are the studies of Jongwon and Bednarz (2012) and Koç \& Demir (2014).

\section{Purpose of Study}

The purpose of this study was to determine the level of map literacy of undergraduate geography students. In the study, the frequency of using map, the frequency of activity by maps and the level of interest in geography are considered as predictive variables in order to determine map literacy of undergraduate geography students, and it was aimed to determine the effect of these variables on the level of map literacy. In Turkish literature, the studies regarding map literacy in geography education are quite insufficient in terms of quality and quantity. Therefore, it is anticipated that this study will serve as a reference for the studies to be conducted on this subject.

\section{Methodology}

\section{Research Design}

In this study, the relational survey model was used. The survey research is the studies with the objective of data collection in order to determine the certain characteristics of a target group (Büyüköztürk et. al, 2009: 16). According to Karasar (1999: 77), the survey models are research approaches used to describe a condition, which is currently available or was available in past, the way it is.

\section{Study Group}

The study group consists of 391 undergraduate geography students studying in the faculty of letters of three different state universities in 2016-2017 academic year. The measurement tool was first applied to 400 undergraduate geography students, and then this number was reduced to 391 during the data extraction process. $231(59.1 \%)$ of the participants are male and $160(40.9 \%)$ are female. The descriptive statistics regarding the undergraduate students' frequency of using map, the frequency of activity by maps and the level of interest in geography, which are considered as independent (predictive) variables, are given in the Table 1. 
Table 1

Descriptive Statistics Regarding the Predictive Variables

\begin{tabular}{lllllllll}
\hline \multirow{2}{*}{ Variable } & \multicolumn{9}{c}{ Alternative } \\
\cline { 2 - 10 } & Never & \multicolumn{3}{c}{ Rarely } & \multicolumn{2}{c}{ Moderate } & \multicolumn{2}{c}{ Frequently } \\
\cline { 2 - 10 } & $\mathrm{f}$ & $\%$ & $\mathrm{f}$ & $\%$ & $\mathrm{f}$ & $\%$ & $\mathrm{f}$ & $\%$ \\
\hline Frequency of using map & 80 & 20.05 & 191 & 48.8 & 100 & 25.6 & 20 & 5.1 \\
\hline $\begin{array}{l}\text { Frequency of activity by } \\
\text { maps }\end{array}$ & 175 & 44.8 & 148 & 37.9 & 50 & 12.8 & 18 & 4.6 \\
\hline Interest in geography & 54 & 13.8 & 106 & 27.1 & 152 & 38.9 & 79 & 20.2 \\
\hline
\end{tabular}

According to the data given in the Table 1, it was determined that $80(20.5 \%)$ of the students never use, 191 (48.8\%) rarely use, 100 (25.6\%) use in medium-level and 20 $(5.1 \%)$ frequently use maps. It was determined that $175(44.8 \%)$ of students never carry out an activity, $148(37.9 \%)$ rarely carry out activities, $50(12.8 \%)$ carry out activities in medium-level and $18(4.5 \%)$ frequently carry out activities by using maps. It was determined that $54(13.8 \%)$ of participants have no interest, $106(27.1 \%)$ are rarely interested, $152(38.9 \%)$ are interested in medium-level and $79(20.2 \%)$ are very interested in geography.

\section{Data Collection Tools}

The Map Literacy Scale called as "Developing Valid and Reliable Map Literacy Scale" developed by Koç \& Demir (2014) was used as the data collection tool in order to determine the level of map competence of undergraduate geography students. The measurement tool of this study consists of two parts. In this first part, the variables such as sex, frequency of using map, frequency of activity by maps, objective of map using, mostly-used type of map and level of interest in geography of the undergraduate geography students included in the study are used. The map literacy scale used in the second part, consists of five factors which are map knowledge and skill test, ability of conducting activities by maps, map reading and interpretation, outline mapping and map use. The first of these factors is designed to determine the map knowledge of students and consists of 23 items. The $\mathrm{KR}_{20}$ reliability coefficient of the test for map knowledge was determined as .76 (Koç \& Demir, 2014).

The map competence scale with five-point likert scale consists of four factors. According to the results of the exploratory and confirmatory factor analyses conducted in the validity and reliability studies, the scale consists of 4 aspects. The scale consists of 24 items in total, 4 of which are in terms of activities by maps, 9 are in map reading and interpretation, 3 are in outline mapping and 8 are in map use. The factor loads of these items included in the scale vary between .46 and .76 . The correlations of 24 items included in the sufficiency of Map Literacy scale are between .51 and .75 . In the paired comparisons, it was determined that there is a positive and moderate (.42-.68) relationship among four factors of the scale, and there is a positive and strong $(.70, .78$, $.80, .90)$ relationship in total (Koç \& Demir, 2014). 


\section{Data Analysis}

First, the levels of undergraduate students were determined by averaging their total points obtained from two scales. A standardized maximum point (60) obtained in all aspects was determined. Then, the multipliers were determined to calculate the minimum and maximum points to be obtained in each aspect based on this standardized point.

In the study, the statistical analyses were carried out by using SPSS 22 (Statistical Package for Social Science for Personal Computers) program. In the calculation of relationships between variables, Pearson Product Moment Correlation (r) was used. The multiple linear regression analysis technique was used between the levels of map literacy and the frequency of using map, the frequency of activity by maps and the level of interest in geography of undergraduate geography students. In the interpretation of regression analyses, the standardized Beta $(\beta)$ coefficients and the results of t-tests regarding their significance were considered. The level of significance was taken as .05 in the analysis of data.

\section{Findings}

\section{Findings Regarding the Determination of the Levels of Map Literacy of Undergraduate Geography Students}

In the research problem, it was assessed if there is a significant relationship between the map literacy points and the frequency of using map, the frequency of activity by maps and the level of interest in geography of undergraduate geography students or not. The multiple linear regression analysis was carried out to determine the relevant relation. The results of the analysis are given in the Table 2 .

Table 2

Results of Multiple Linear Regression Analysis regarding the Determination of Map Literacy of Undergraduate Geography Students

\begin{tabular}{|c|c|c|c|c|c|c|c|}
\hline Variable & B & $\begin{array}{r}\text { Standard } \\
\text { Error }\end{array}$ & $\boldsymbol{\beta}$ & $\mathbf{t}$ & $\mathbf{p}$ & $\begin{array}{c}\text { Zero } \\
\text { order } r\end{array}$ & Partial $\mathbf{r}$ \\
\hline Invariant & 51.180 & 3.472 & & 14.743 & .000 & & \\
\hline $\begin{array}{l}\text { Frequency of } \\
\text { using maps }\end{array}$ & 7.363 & 1.459 & .249 & 5.047 & .000 & .444 & .248 \\
\hline $\begin{array}{l}\text { Frequency of } \\
\text { activity with } \\
\text { maps }\end{array}$ & 3.985 & 1.327 & .141 & 3.002 & .003 & .349 & .151 \\
\hline $\begin{array}{l}\text { Level of } \\
\text { interest in } \\
\text { geography }\end{array}$ & 7.746 & 1.213 & .311 & 6.386 & .000 & .474 & .309 \\
\hline $\begin{array}{l}\mathrm{R}=.554 \\
\mathrm{~F}_{(3-387)}=57.103\end{array}$ & $\begin{array}{l}\mathrm{R}^{2}=.3 \\
\mathrm{p}=.0\end{array}$ & & & & & & \\
\hline
\end{tabular}


According to the regression analysis results given in the Table 2; it was determined that the correlation coefficient between two variables is $\mathrm{r}=.44$ when controlling other positive and moderate $(\mathrm{r}=.25)$ variables between the level of map literacy and the frequency of using map of undergraduate geography students in the analysis of binary and partial correlations between the predictive variables and dependent variable. There is a positive and medium-level relationship ( $\mathrm{r}=.35)$ between the level of map literacy and the frequency of activity by map variables of undergraduate geography students. In the control of other variables, the correlation between two variables was determined as .15. There is a positive and moderate relationship ( $\mathrm{r}=.47)$ between the level of map literacy and the level of interest in geography variables of undergraduate geography students. However, in the control of other variables, the correlation between two variables was determined as .31.

Also, it was determined that there is a moderate and significant relationship between the level of map literacy and the frequency of using map, the frequency of activity by map and the level of interest in geography variables. It explains approximately $31 \%$ of the total variance with these relevant three variables.

According to the standardized regression coefficient $(\beta)$, the relative order of importance of predictive variables regarding the level of map literacy is the level of interest in geography, the frequency of using map and the frequency of activity by maps respectively. When examining the t-test results regarding the significance of regression coefficients, it was determined that the frequency of using map, the frequency of activity by maps and the level of interest in geography variables are a significant predictor on the level of map literacy of undergraduate geography students.

According to the regression analysis results, the regression equation regarding the determination of the level of map literacy of undergraduate geography students is given below.

Map Literacy=51.180+7.363FUM+3.985FAM+7.746LIG.

The normality and linearity hypothesis regarding the data obtained from the study group are given in the following graphs. 


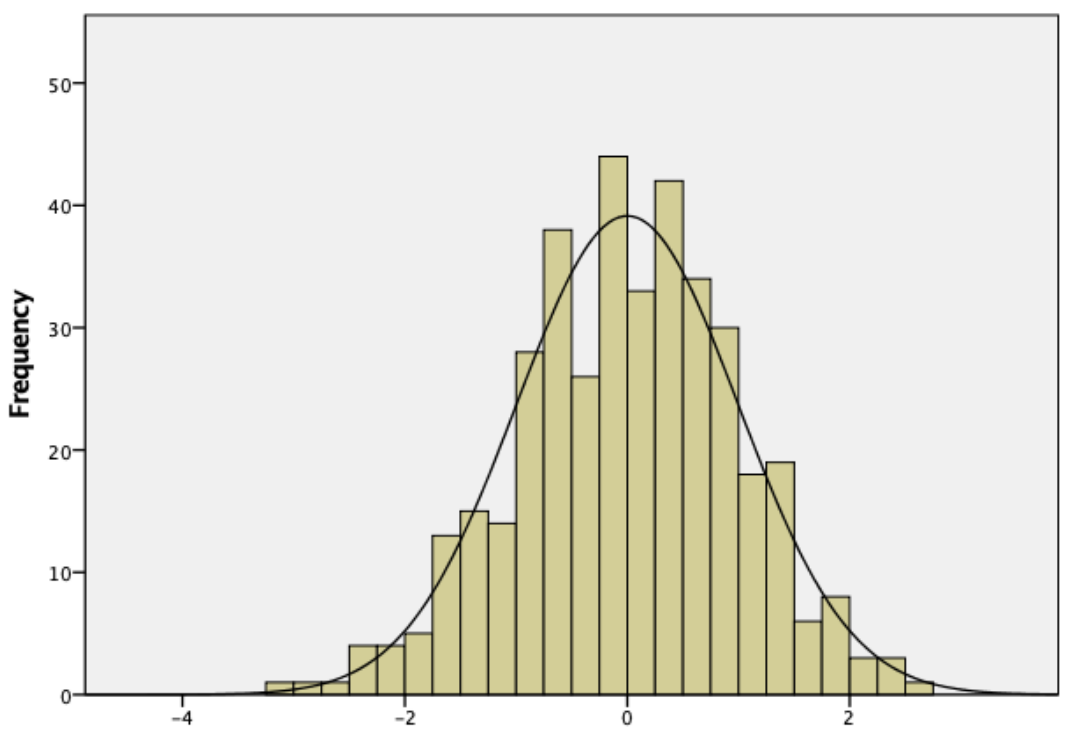

Figure 1. Assumption of normality regarding map literacy scores of geography undergraduate students

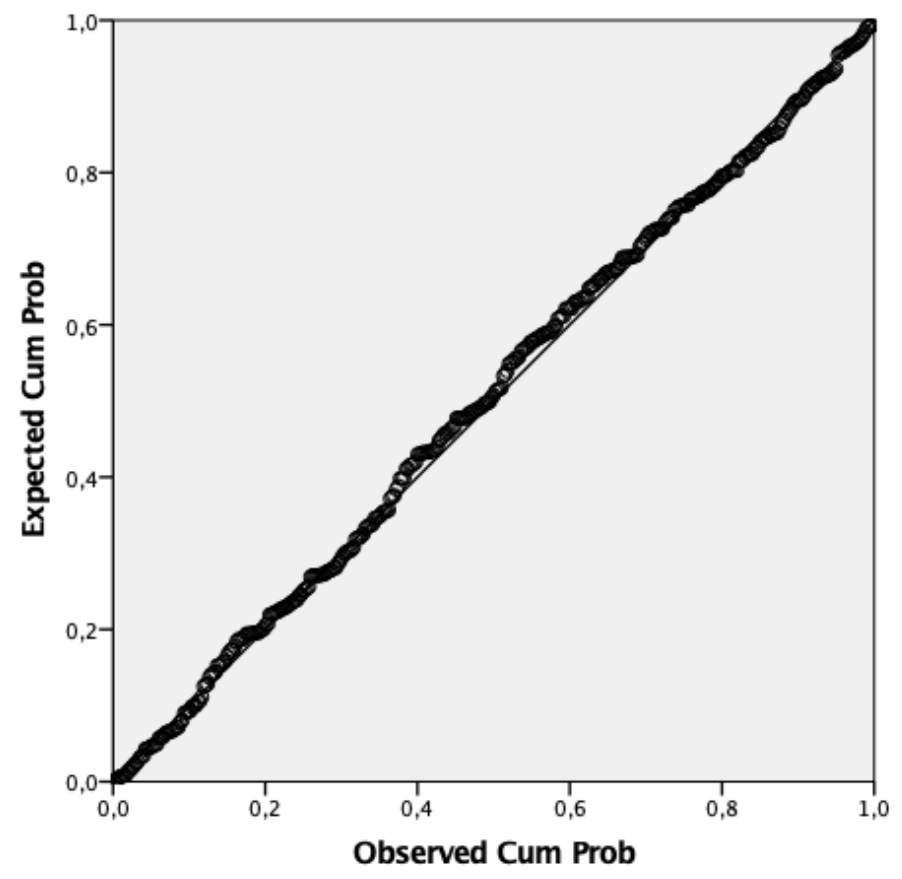

Figure 2. Assumption of linearity regarding map literacy scores of geography undergraduate students. 


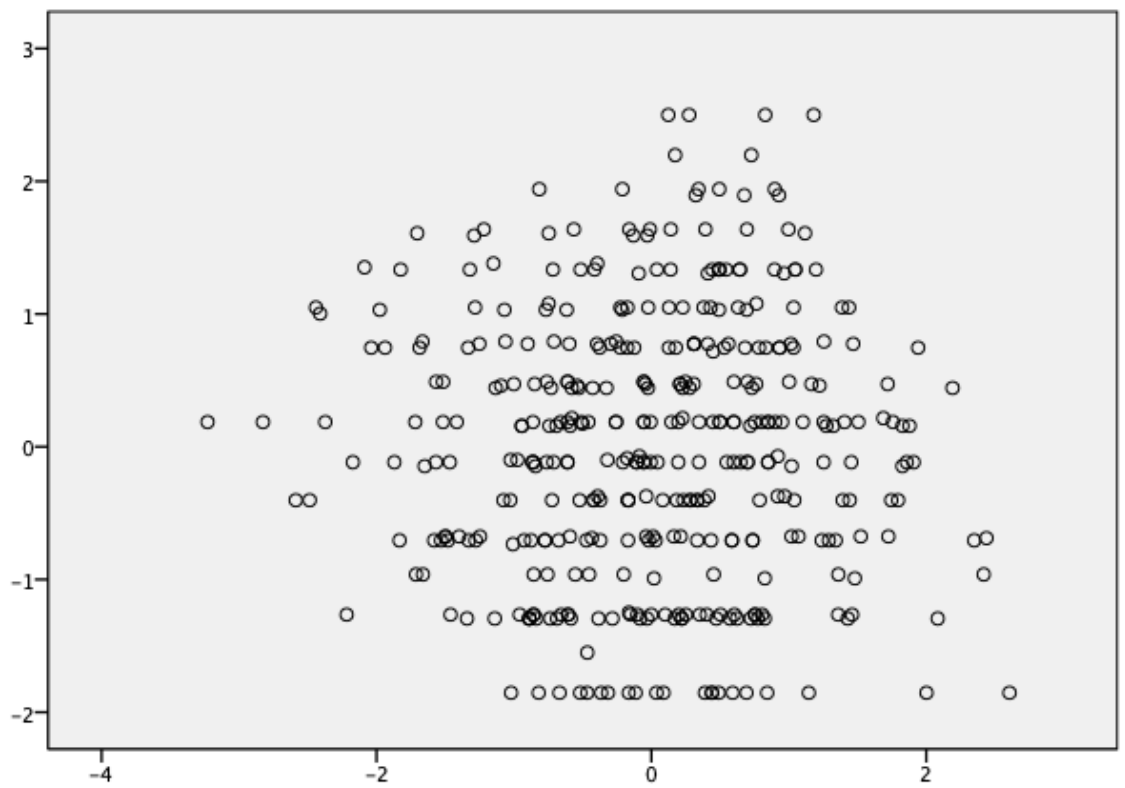

Figure 3. Regression standardized residual map literacy scores of geography undergraduate students.

\section{Result and Discussion}

This study was conducted to determine the level of geography literacy of undergraduate geography students. In this scope, the map literacy point obtained from the level of map-use competence and map knowledge-skill scales, to which the study group is subjected, is the dependent variable, and the frequency of using map, the frequency of activity by maps and the level of interest in geography variables are the independent variables of this study. The results obtained from the research with the relational survey model are given below.

According to the findings obtained from the research; when the correlations between the predictive variables and the dependent variable were examined, a positive and moderate correlation was seen between the level of map literacy of geography preservice teachers and variables such as competence in the frequency of using map, the frequency of activity by maps, and the level of interest in geography.

When examining the partial correlation coefficients determined by controlling the other variables between the predictive variables and dependent variable, it was determined that there is a positive and weak relationship between the level of map literacy and the frequency of using map and the frequency of activity by maps variables of undergraduate geography students. On the other hand, it was determined that 
undergraduate geography students had a positive and moderate relationship between the level of map literacy and the level of interest in geography.

Also, it was determined that there is a moderate and significant relationship between the map literacy and the frequency of using map, the frequency of activity by map and the level of interest in geography variables.

According to the research results, it was determined that the map skills of undergraduate geography students are a significant predictor of their map literacy.

In their study conducted to determine the level of map-use competence of undergraduate geography students, Aksoy and Koç (2017) determined that there is a positive and moderate relationship between the level of map-use competence and the ability of conducting activities by using maps and outline mapping variables; and there is a positive and high-level relationship between the level of map-use competence and the map reading and interpretation and map use variables. When the partial correlations are examined, it was determined that there is a positive and high-level relationship between the level of map-use competence and the ability of conducting activities by maps, map reading and interpretation, outline mapping and map use variables.

Aksoy and Ablak (2017) determined that there is a positive and moderate relationship between the level of map literacy and the competency level of conducting activities by using maps, map reading, outline mapping and map use of undergraduate social studies students. When examining the partial correlations between the predictive variables and dependent variables, it was determined that there is a positive and moderate relationship between the level of map literacy and the competency level of conducting activities by using maps, map reading and interpretation of undergraduate social studies students. On the other hand, it was determined that undergraduate social studies students had a positive and weak relationship between the level of map literacy and the competency level of overall mapping and map use variables. Also, it was determined that there is a moderate and significant relationship between the level of map literacy and the ability of conducting activities by maps, map reading and interpretation, overall mapping and map use variables.

The study results show that the map skills are the important components of map literacy. These results are similar to the results of the studies carried out by Aksoy (2013), Koç \& Karatekin (2015), Koç \& Çifçi (2016), Koç, Aksoy \& Çifçi (2017).

Aksoy (2013) determined that the variables such as sex, possession of a book of maps, department and field of study have an impact on the points of undergraduate students obtained in 8 map skills. Also, the level of map skills of undergraduate geography and social studies students and the students

According to the results of the study conducted by Koç, Aksoy \& Çifçi (2017), the levels of map literacy (knowledge-skill and competence) of undergraduate students were significantly different depending on the variables such as sex, faculty, the frequency of using map, the level of participation to various activities, the objective of map use in daily life and the level of interest in geography. It was determined that the 
relevant differences were in favor of male students, Faculty of Medicine, Dentistry students, those with high level of map use, those frequently participating in activities and those very interested in geography.

The study results indicate that the frequency of using map and the level of interest in geography are a significant predictor on the map literacy of undergraduate geography students. This result is similar to the results of the study carried out by Aksoy \& Ablak (2017), Aksoy \& Koç (2017).

Similar to the above-mentioned results of the study conducted by Aksoy \& Ablak (2017), it was determined that there is a moderate and significant relationship between the level of map literacy and the ability of conducting activities by maps, map reading and interpretation, overall mapping and map use variables.

Aksoy \& Koç (2017) determined that there is a high-level and significant relationship between the level of map-use competence and the ability of conducting activities by maps, map reading and interpretation, overall mapping and map use variables of undergraduate geography students.

The study results indicate that the frequency of using map and the level of interest in geography are a significant predictor on the map literacy of undergraduate geography students.

Koç \& Karatekin (2015) determined that the social studies teacher candidates' map knowledge is limited, and their activity by maps, map reading and interpretation, overall mapping and map use skills are moderate.

Accoding to the results of Koç \& Çifçi (2016), primary school teacher candidates have a moderate-level map literacy. When examining the impact of various variables on the map literacy of primary school teacher candidates, there was a difference in favor of male teachers in terms of mapping and map use based on the sex variable. Based on the frequency of using map variable, there was a difference in favor of teacher candidates with high level of map use depending on their map reading and interpretation, mapping and map literacy points in all aspects. Based on the level of interest in geography variable, it was determined that there is a difference in favor of teacher candidates very interested in geography in terms of map use points of primary school teacher candidates.

In the study conducted by Erol (2017), it was determined that 7 th-grade students have a moderate level map literacy. It was determined that the students did not sufficiently practiced the information they had learned during the course on the map and that their geographical knowledge did not sufficiently improve due to a lack of interpreting geographical information. It was concluded that the lack of sufficient activities in map literacy in social studies workbooks adversely affected the development of this skill. 


\section{Suggestions}

The study results indicate that the frequency of using map and the level of interest in geography are a significant predictor on the map literacy of undergraduate geography students. Accordingly, it is suggested to focus on courses and practices to develop the map knowledge/skills/competence in undergraduate geography programs in order to use the map, which is one of most important method of expression in the discipline of geography, as a teaching aid much more effectively. In addition, it is suggested that the courses should be supported with technological materials in order to draw the interest of students.

\section{References}

Aksoy, B. (2013) Investigation of Mapping Skills of Pre-Service Teachers as Regards to Various Parameters. Educational Research and Reviews, 8(4), 134-143.

Aksoy, B. \& Ablak, S. (2017). Exploring map literacy of social studies undergraduate students. Academic Conference on Education, Teaching and E-learning 11-14 August, Prague, 657.

Aksoy, B. \& Koç. H. (2017). Exploring map proficiency levels of undergraduate geography students. $7^{\text {th }}$ International Congress of Research in Education, 27-29 April, Çanakkale, 337.

Buckley, A. R., Muehrcke, P. C. \& Muehrcke, J. O. (2011). MapUse: Reading, Analysis and Interpretation. Redlands, CA: Esri Press.

Büyüköztürk, Ş., Çakmak, K. E., Akgül, E. Ö., Karadeniz, Ş. \& Demirel, F. (2009). Bilimsel Araştırma Yöntemleri. Ankara: Pegem Akademi.

Carswell, R. J. B. (1971). The Role of the user in the map communication process: children's abilities in topographic map reading. Cartographica. The International Journal for Geographic Information and Geovisualization, 8(2), 40-45.

Catling, S. J. (1998). Geographical Work in Primary and Middle Schools. Sheffield: Geographical Association.

Clarke, D. (2003). Are you functionally map literate?, Proceedings of the 21st International Cartographic Conference (ICC). South Africa: Durban. 10-16 August, 713-719.

Erol, H. (2017). An Evaluation on Secondary School Students' Map Literacy Skills. Anadolu Journal of Educational Sciences International, 7(3), 425-457.

Fouberg, H. E., Murphy, A. B. \& Blij, H.J. (2012). Human Geography. USA: Wiley Plus.

Gerber, R. \& Wilson, P. (1989). Using maps well in the geography classroom. In J. Fien., R. Gerber \& P. Wilson (Ed.), The geography teacher's guide to the classroom. Melbourne: Macmillan.

Gilmartin, P. P. \& Patton, J. C. (1984). Comparing the sexes on spatial abilities: map-use skills. Annals of the Association of American Geographers, 74(4), 605-619.

Golledge, R. G., Marsh, M. \& Battersby, S. (2008). Matching geospatial concepts with geographic educational needs. Geographical Research, 46(1), 85-98. 
Gökçe, N. (2015). Social Studies in Improving Students' Map Skill: Teachers' Opinions. Educational Sciences: Theory \& Practice, 15(5), 1345-1362.

Harita Genel Müdürlüğ̈̈. https://www.harita.gov.tr/images/egitim/87245f4b1d0d12c.pdf (adresinden erişildi).

Jongwon, L. \& Bednarz R. (2012). Components of spatial thinking: evidence from a spatial thinking ability test. Journal of Geography, 111(1), 15-26).

Karasar, N. (1999). Bilimsel Araştırma Yöntemi. Ankara: Nobel Yayınları.

Kartal, F. \& Koç, H. (2017), Examination of Map Literacy Levels of Secondary Levels Students (9 th Grade) in Terms of Certain Variables, Eastern Geographical Review, 22(37), 179198.

Kızılçaoğlu, A. (2007). A pedagogical overview of map skills. The Journal of Institute of Social Sciences, 18, 341-358.

Krygier, J. \& Wood, D. (2005). Making Maps. New York: The Guilford Press.

Koç, H. (2008). The effect of the gains at the program of geography teaching on skill levels of mapping of the students. ( $\mathrm{PhD}$ Thesis), Gazi University Institute of Educational Sciences.

Koç, H. (2010). Map perception and usage in geography education. National Education, 87, 146-158.

Koç, H. \& Bulut, İ. (2014). An Investigation into the Impacts of Gestalt Theory on Learners' Map Literacy Skills. Marmara Geographical Review, 30(1), 1-19.

Koç, H. \& Demir, S. B. (2014). Developing valid and reliable map literacy scale. Review of International Geographical Education, 4(2), 120-136.

Koç, H. \& Karatekin, K. (2015). An examination of map literacy levels of prospective social studies teachers in terms of various variables. $4^{\text {th }}$ USBES. Bolu.

Koç, H. \& Çifçi, T. (2016). An investigation into map literacy levels of elementary school teacher candidates based on various variables, Marmara Geographical Review, 34, 920.

Koç, H., Aksoy, B.\& Çifçi, T. (2017) An examination of map literacy levels of students from various undergraduate programmes according to several variables: Cumhuriyet university sample. Erzincan University Journal of Education Faculty, 31(1), 301-321.

Liben, L. \& Downs, R. (1989). Understanding Maps as Symbols: the Development of Map Concepts in Children. New York: Academic Press.

Mac Eachren, M. (2004). How Maps Work. New York: The Guilford Press.

McClure, R. W. (1992). A conceptual model for map skills curriculum development based upon a cognitive field theory philosophy. (Unpublished Doctoral Dissertation, Oklahoma State University, Oklahoma).

Olson, J. M. (1976). A coordinated approach to map communication improvement. The American Cartographer, 3(2), 151-159.

Rautenbach, V. Coetzee, S. \& Çöltekin, A. (2017). Development and evaluation of a specialized task taxonomy for spatial planning - A map literacy experiment with topographic maps, ISPRS Journal of Photogrammetry and Remote Sensing, 127:16-26. 
Richard, B.,Schultz, J. \&Kerski J. \&Todd, C. P. (2008). The use of virtual globes as a spatial teaching tool with suggestions for meta data standards. Journal of Geography, 107(1), 2734.

Sönmez, Ö.F. \& Aksoy, B. (2012). Determination of primary education secondary stage students' map skill levels. Turkish Studies-International Periodical for the Languages, Literature and History of Turkish or Turkic 7(1):1905-1924.

Weeden, P. (1997). Learning through maps. D. Tilbury \& M. Williams (Eds.), Teaching and learning geography, In (pp. 168-179). London: Routledge.

White, S. H. (1995). An examination of the effects of mixed-age grouping on learning map reading skills (Unpublished Dissertation), Texas: A \& M University.

Wiegand, P. (2006). Learning and Teaching with Maps. New York: Routledge.

Wood, D. (1992). The Power of Maps. New York: The Guilford.

\section{Biographical Statement}

Bülent AKSOY is an associate professor at Gazi University. His research interests are Geography Education, Social Studies Education and Political Geography studies. 